\title{
Macroscopic Findings Supplemental Qualifiers Dataset
}

National Cancer Institute

\section{Source}

National Cancer Institute. Macroscopic Findings Supplemental Qualifiers Dataset. NCI Thesaurus. Code C147221.

A dataset containing supplemental information, specifically non-standard variables, to parent records in the macroscopic findings domain. 